Borneo Journal of Phamascientech, Vol. 04, No. 02, Oktober Tahun 2020

ISSN-Print. 2541-3651

ISSN-Online. 2548 - 3897

Research Article

\title{
ANALISIS KETEPATAN TERAPI DAN KEPATUHAN KONSUMSI OBAT TERHADAP GLUKOSA DARAH PUASA PADA PASIEN DM TIPE II DI PUSKESMAS PEKUNCEN
}

\section{ANALYSIS OF ACCURACY OF THERAPY AND COMPLIANCE WITH DRUGS ON FASTING BLOOD GLUCOSE IN TYPE IIDM PATIENTS BASIC HEALTH SERVICESIN PEKUNCEN}

\author{
Aziez Ismunandar* dan Luthfi Hidayat Maulana \\ Universitas Peradaban \\ *aziez4183@gmail.com
}

\begin{abstract}
ABSTRAK
Prevalensi nasional penyakit DM sebanyak 2,1\% dari total penduduk sebanyak 250 jiwa pada tahun 2013. Prevalensi DM pada tahun 2013 di Jawa Tengah berdasarkan RISKESDAS berada di peringkat13 yaitu sebanyak $1,9 \%$ dari total penduduk 24.084.433.Di Kabupaten Banyumas sebanyak 2,2\%. Sedangkan di Kota Purwokerto sendiri terdapat 1992 jumlah kasus diabetes melitus pada tahun 2016. Tujuan penelitan mengetahui pengaruh kepatuhan terapi dan kepatuhan minum obat terhadap gluosa darah puasa pada pasien DM tipe 2. Metode penelitian menggunkan survei analitik dengan teknik cross sectional, dengan jumlah sampel sebanyak 35 pasien DM tipe II. Analisis data menggunakan uji regresi linier. Hasil menunjukan sebanyak 62,9\% dan 37,1\% pasien dengan kadar glukosa darah tidak tercapai dan tercapai. Pasien dengan kategori ketepatan terapi dan tidak tepat adalah $45,7 \%$ dan 54,3\%. Pasien dengan kepatuhan tinggi sebanyak $68,6 \%$. Uji regresi linear berganda menunjukan adanya pengaruh ketepatan terapi obat antidiabetes oral dengan kadar gula darah puasa pada pasien DM tipe II dengan nilai sig. sebesar 0,004. Kesimpulan Terdapat pengaruh antara ketepatan terapi obat antidiabetes oral dengan glukosa darah darah puasa di Puskesmas Pekuncen.
\end{abstract}

Kata kunci: DM, Ketepatan terapi, kepatuhan konsumsi obat 
Borneo Journal of Phamascientech, Vol. 04, No. 02, Oktober Tahun 2020

ISSN-Print. 2541-3651

ISSN-Online. 2548 - 3897

ResearchArticle

ABSTRACT

The national prevalence of DM was $2.1 \%$ of the total population of 250 people in 2013. The prevalence of DM in 2013 in Central Java based on RISKESDAS was in 13th place, which was $1.9 \%$ of the total population of $24,084,433$. In Banyumas Regency as much as 2 , 2\%. Meanwhile, in the city of Purwokerto there were 1992 cases of diabetes mellitus in 2016. The aim of the study was to determine the effect of therapy adherence and medication adherence to fasting blood gluosa in type 2 DM patients. type II DM patients. Data analysis using linear regression test. The results showed that $62.9 \%$ and $37.1 \%$ of patients with blood glucose levels were not reached and reached. Patients with therapy accuracy and inappropriate categories were $45.7 \%$ and $54.3 \% .68 .6 \%$ of patients with high adherence. Multiple linear regression test shows the effect of the accuracy of oral antidiabetic drug therapy with fasting blood sugar levels in type II DM patients with a sig value. equal to 0.004 . Conclusion There is an influence between the accuracy of oral antidiabetic drug therapy with fasting blood glucose at Pekuncen Health Center.

Keywords: Diabetes mellitus, accuracy of therapy, adherence to taking medication 
Borneo Journal of Phamascientech, Vol. 04, No. 02, Oktober Tahun 2020

ISSN-Print. 2541-3651

ISSN-Online. 2548 - 3897

ResearchArticle

\section{PENDAHULUAN}

World Health Organization menyatakan 422 juta orang dewasa berusia di atas 18 tahun hidup dengan diabetes pada tahun 2014. Penderita dengan jumlah tertinggi diperkirakan tersebar di Asia Tenggara dan Pasifik Barat yang merupakan setengah kasus DM di dunia. Jumlah penderita diabetes di dunia telah meningkat secara signifikan sejak tahun 1980 hingga 2014, meningkat dari 108 juta menjadi 422 juta atau hampir $400 \%$. Prevalensi nasional penyakit kronis, salah satunya yaitu DM sebesar 2,1\% dari total penduduk sesuai dengan RISKESDAS tahun 2013. DM menyebabkan 1,5 juta kematian pada tahun 2012 (KemenKes RI, 2018).

Pasien diabetes tipe2 (DM Tipe 2) dengan level glukosa darah tidak terkontrol dapat meningkatkan risiko komplikasi mulai dari akut hingga kronik. DM Tipe 2 dengan komplikasi dapat berpengaruh terhadap pengontrolan level glukosa darah serta dapat mempercepat terjadinya insulin resistance (American Diabetes Association, 2013). Pengontrolan glukosa darah salah satunya dilakukan menggunakan intervnsi obat. Pilihan obat yang tersedia ternyata memberikan masalah tersendiri dalam praktik, terutama ketepatan pemilihan dan penggunaan obat secara benar dan safety, sehingga perlu diketahui secara rinci obat apa yang digunakan dan dapat memberikan manfaat klinik yang optimal bagi pasien (Landani, 2018). Ketidaktepatan pemilihan terapi akan mempengaruhi outcome terapi pasien. Penggunaan obat yang tidak tepat memberikan dampak negatif berupa kemungkinan terjadinya efek samping yang tidak diharapkan, timbulnya resistensi obat, interaksi obat, pemborosan anggaran, dan secara tidak langsung akan menurunkan mutu pelayanan pengobatan dan pelayanan kesehatan (Maryanti, 2019).

Berdasarkan uraian tersebut penelitian ini ingin menganalisis pengaruh ketepatan terapi dan kepatuhan minum obat terhadap glukosa darah puasa pada pasien DM tipe 2 di Puskesmas Pekuncen. 
Borneo Journal of Phamascientech, Vol. 04, No. 02, Oktober Tahun 2020

ISSN-Print. 2541-3651

ISSN-Online. 2548 - 3897

ResearchArticle

\section{METODOLOGI}

\section{Jenis, Tempat dan Waktu Penelitian}

Penelitian ini menggunakan survei analitik yang mencoba menggali bagaimana dan mengapa fenomena kesehatan itu terjadi dengan menggunakan rancangan penelitian cross sectional analitik di Puskesmas Puskesmas Pekuncen pada bulan Februari-Juli 2020.

\section{Instrumen Penelitian}

Pengambilan data menggunakan kuesioner dan rekam medis (sosio demografi dan obat yang diresepkan). Pengukuran kepatuhan menggunakan MARS yang telah diuji validasi dan reliabelitas pada pasien diabetes di Indonesia (Riyanto, 2017). Penggunaan kuesioner lebih mudah diintegrasikan ke dalam praktek klinis. Kuesioner MARS bergantung pada subjek dalam melaporkan kepatuhan (Sugiyono, 2016). Kuesioner MARS terdiri dari 5 pertanyaan dengan skala frekuensi 1 sampai 5 (selalu, sering, kadangkadang, jarang dan tidak pernah). Kategori kepatuhan dalam peneltian ini terdiri dari tinggi (nilai kepatuhan $\geq$ rata-rata nilai kepatuhan) dan rendah (nilai kepatuhan < rata-rata nilai kepatuhan).

\section{Izin Penelitian}

Penelitian ini telah dikaji dan diperoleh izin dari komite etik Universitas Peradaban (Ethical

Clearance

Ref: 451/GA.2/K.LPPM.061042/VII/2020). Kriteria Inklusi dan Eksklusi

Rekrutmen responden secara random dan memenuhi kriteria inklusi. Kriteria inklusi yakni pasien DM tipe 2 peserta Prolanis berusia 40-80 tahun, memiliki rekam medis lengkap terkait pemeriksaan gula darah rutin, dan bersedia menjadi responden. Kriteria ekslusi yakni pasien yang tidak ada ditempat saat penelitian dilaksanakan atau pasien meninggal dunia.

\section{Sampel Size Penelitian}

Perhitungan sampel size menggunakan total sampling yaitu jumlah sampel yang diambil adalah sampel yang dapat hadir pada saat kegiatan dilaksanakan sebanyak 35 pasien.

\section{Analisis}

Data yang diperoleh dilakukan analisis Chi square dilanjutkan regresi linear untuk mengetahui pengaruh Ketepatan Terapi dan Kepatuhan 
Borneo Journal of Phamascientech, Vol. 04, No. 02, Oktober Tahun 2020

ISSN-Print. 2541-3651

ISSN-Online. 2548 - 3897

ResearchArticle

Minum Obat yang signifikan terhadap HASIL DAN PEMBAHASAN

Kadar Gula Darah Puasa Pada Pasien Pasien berusia 61-80 tahun Diabetes Melitus. Analisis mendominasi dengan persentase $60 \%$. menggunakan SPSS versi 21. Pasien dengan jenis kelamin perempuan sebanyak 24 responsen (69\%). Pasien dengan pekerjaan IRT dan PNS mendominasi yakni masing-masing 8 responden $(23 \%)$. Keseluruhan data dapat dilihat pada Tabel I.

Tabel I. Karakteristik Responden berdasarkan Usia, Jenis Kelamin, Pekerjaan, Tingkat Pendidikan

\begin{tabular}{|c|c|c|c|}
\hline & Demografi Pasien & Frekuensi & Persentase $(\%$ \\
\hline \multirow{2}{*}{ Usia } & 40-60 Tahun & 14 & 40 \\
\hline & 61-80 Tahun & 21 & 60 \\
\hline \multirow{2}{*}{ Jenis Kelamin } & Laki-Laki & 11 & 31 \\
\hline & Perempuan & 24 & 69 \\
\hline \multirow{6}{*}{ Pekerjaan } & IRT & 8 & 23 \\
\hline & Pensiunan & 2 & 6 \\
\hline & Buruh & 9 & 26 \\
\hline & PNS & 8 & 23 \\
\hline & Petani & 6 & 17 \\
\hline & Pedagang & 2 & 6 \\
\hline \multirow{4}{*}{$\begin{array}{l}\text { Tingkat } \\
\text { Pendidikan }\end{array}$} & SD & 8 & 23 \\
\hline & SMP & 6 & 17 \\
\hline & SMA & 10 & 29 \\
\hline & SARJANA & 11 & 31 \\
\hline
\end{tabular}

Distribusi pasien diabetes melitus tipe 2

di Puskesmas Pekuncen Banyumas berdasarkan ketepatan terapi terbanyak adalah katagori tidak tepat sebanyak 19 responden $(54,3 \%)$, kepatuhan minum obat terbanyak adalah katagori patuh 
Borneo Journal of Phamascientech, Vol. 04, No. 02, Oktober Tahun 2020

ISSN-Print. 2541-3651

ISSN-Online. 2548 - 3897

ResearchArticle

rendah sebanyak 24 responden $(68,6 \%)$

$(62,9 \%)$

dan hasil pemeriksaan gula darah puasa

terbanyak adalah katagori target tidak

tercapai sebanyak 22 responden

Tabel II.Karakteristik Responden berdasarkan Ketepatan Terapi, Kepatuhan Minum Obat dan Kadar Gula Darah Puasa

\begin{tabular}{cccc}
\hline & Variabel & Frekuensi & Persentase(\%) \\
\hline Ketepatan Terapi & Tidak Tepat & 19 & 54,3 \\
& Tepat & 16 & 45,7 \\
Kepatuhan & Patuh rendah & 24 & 68,6 \\
Minum Obat & Patuh tinggi & 11 & 31,4 \\
Gula Darah & Target tidak tercapai & 22 & 62,9 \\
Puasa & Target tercapai & 13 & 37,1 \\
\hline
\end{tabular}

Berdasarkan Tabel II menunjukan bahwa tepat dosis adalah kesesuaian dosis obat DM yang diberikan meliputi dosis, jumlah takaran, dan frekuensi pemberian obat berdasarkan standar PERKENI 2015. Dosis yang diberikan dari puskesmas sudah sesuai dengan standar yang ditentukan. Menurut Megantari (2015), dikatakan tidak tepat cara pakai yaitu apabila cara penggunaan obat tidak tepat, mencakup jumlah dosis, cara pemberian, frekuensi pemberian dan durasi pemberian. Salah satu yang penyebabkan ketidakefektivan terapi obat ialah penggunaan under dose untuk menghasilkan respon yang terapi dikehendaki dan konsentrasi obat dalam plasma darahpasien yang berada dibawah indeks terapi yang ditetapkan (Samoh, 2014). Teori tersebut yang menyimpulkan pasien tidak tepat terapi dikarenakan ada sisa obat sehingga pasien tersebut berarti tidak tepat cara pakai dan tidak tepat dosis karena telah mengurangi konsumsi obat yang telah ditetapkan. Tingkat kepatuhan adalah penilaian kepada pasien yang digunakan 
Borneo Journal of Phamascientech, Vol. 04, No. 02, Oktober Tahun 2020

ISSN-Print. 2541-3651

ISSN-Online. 2548 - 3897

ResearchArticle

untuk mengetahui apakah pasien telah mengikuti petunjuk penggunaan obat selama menjalani pengobatan (Rasdianah et al., 2016). Berdasarkan penelitian yang telah di lakukan, mayoritas pasien memiliki tingkat kepatuhan yang rendah. Hal tersebut menggambarkan bahwa masyarakat kurang menyadari pentingnya menjaga kesehatan dan mulai menyadari pentingnya mematuhi anjuran tenaga kesehatan dalam hal pemberian obat yang harus di konsumsi sesuai dosis, sesuai waktu dan periode minum obat yang dianjurkan oleh tenaga kesehatan. Pemeriksaan glukosa darah puasa $\geq 126$ mg/dl. Puasa adalah kondisi tidak adanya asupan karbohidrat/ kalori selama minimal 8 jam (PERKENI, 2015). Berdasarkan data sunjek yang diteliti, kejadian ini dimungkinan disebabkan karena ada pasien yang tidak tepat dalam menkonsumsi obat DM.

Tabel III. Hasil analisis regresi pengaruh ketepatan dan kepatuhan terhadap kadar gula darah puasa

\begin{tabular}{cccccccc}
\hline \multicolumn{2}{c}{ Variabel } & $\begin{array}{c}\text { Koefisien } \\
\text { Regresi }\end{array}$ & S.E. & Wald & df & Sig. & Exp(B) \\
\hline Kadar Gula & Ketepatan & 3,688 & 1,295 & 8,108 & 1 & 0,004 & 39,959 \\
Darah Puasa & Kepatuhan & 0,574 & 1,117 & 0,264 & 1 & 0,607 & 1,776 \\
& Constant & $-7,191$ & 2,242 & 10,283 & 1 & 0,001 & 0,001 \\
\hline
\end{tabular}

Log odds $($ Kadar Gula Darah Puasa $)=$ Constanta $+\mathrm{X}_{1}+\mathrm{X}_{2}$

$$
Y_{1}=-7,191+3,688 X_{1}+0,574 X_{2}
$$

Keterangan:

$\mathrm{X}_{1} \quad=$ Ketepatan terapi obat

$\mathrm{X}_{2} \quad=$ Kepatuhan

$\mathrm{Y} \quad=$ Kadar glukosa darah puasa

Berdasarkan Tabel III bahwa hasil terhadap kadar gula darah puasa analisis regresi berganda menunjukan diperoleh nilai sig. value $=0,004$ ketepatan terapi obat lebih berpengaruh $\quad(<0,05)$, artinya terdapat pengaruh 
Borneo Journal of Phamascientech, Vol. 04, No. 02, Oktober Tahun 2020

ISSN-Print. 2541-3651

ISSN-Online. 2548 - 3897

ResearchArticle

signifikan antara ketepatan terapi obat terhadap kadar gula puasa. Persamaan regresi linear berganda menunjukan koefisien X1 (ketepatan terapi obat) memiliki nilai tertinggi $(3,688)$ artinya, ketepatan terapi obat paling berpengaruh positif terhadap penurunan kadar glukosa darah puasa jika dibandingkan dengan koefisien X2 (kepatuhan). Hasil tersebut sejalan dengan penelitian Maulana (2019) yang menunjukan ketepatan berpengaruh terhadap penurunan kadar gula darah. Dosis yang terlalu rendah menjadi salah satu penyebab ketidakefektifan terapi obat untuk menghasilkan respon yang diinginkan dan konsentrasi obat dalam darah pasien yang berada dibawah indeks terapi (Samoh, 2014). Pemakaian obat tidak rasional memberikan kerugian antara lain seperti dampak klinik (seperti penyakit tidak sembuh atau makin parah dan memicu timbulnya efek samping) dan dampak ekonomi (Keban, 2016). Uraian tersebut menyimpulkan ketika pasien tidak tepat cara pakai maka tidak tepat dosis, hal ini berarti pasien tersebut tidak tepat terapi obat. Penelitian ini dilakukan pada 1 unit pelayanan kesehatan, maka

selanjutnya perlu dilakukan penelitian pada unit pelayanan yang lebih luas sehingga diperoleh responden yang lebih besar.

\section{KESIMPULAN}

Berdasarkan hasil penelitian terdapat pengaruh antara ketepatan terapi obat antidiabetes oral dengan glukosa darah darah puasa pada pasien DM tipe 2 di Puskesmas Pekuncen yakni dengan nilai sig. value sebesar 0,004 dan koefisien regresi 3,688.

\section{DAFTAR PUSTAKA}

American Diabetes Association. 2013. Economic Costs of Diabetes in the U.S. in 2013. Diabetes Care, 36: 1033-1046.

Keban, S. A., \& Ramdhani, U. A. 2016. Hubungan Rasionalitas Pengobatan dan Self-care dengan Pengendalian Glukosa Darah pada Pasien Rawat Jalan di Rumah Sakit Bina Husada Cibinong.Jurnal Ilmu Kefarmasian Indonesia, volum 14 (No. 1), Hal. 66-72. Fakultas Farmasi Universitas Pancasila. Jakarta.

Kementerian Kesehatan RI. 2018.Pusat Data dan Informasi Kementerian Kesehatan RI. Jakarta. 
Borneo Journal of Phamascientech, Vol. 04, No. 02, Oktober Tahun 2020

ISSN-Print. 2541-3651

ISSN-Online. 2548 - 3897

ResearchArticle

Landani, A. (2018). Hubungan Aktivitas

Indonesia, 5(4), 249-257.

Fisik dengan Gula Darah Puasa

Terkontrol Pada Penderita

Diabetes Melitus Tipe 2 Peserta

Prolanis di Bandar Lampung.

Univeritas Lampung.

Maryanti, R. (2019). Hubungan Kepatuhan Minum Obat Terhadap Peningkatan Tekanan Darah Pada Penderita Hipertensi. Sekolah Tinggi Ilmu Kesehatan Insan Cendekia Medika.

Maulana, Luthfi H., 2019. Kajian Psidium Guajava Linn Dan Moringa Oleivera Lamk Terhadap Perilaku Mencit Yang Diinduksi Diabetes Mellitus Tipe 2. Jurnal Para Pemikir. Politeknik Harapan Bersama Tegal.

Megantari, N. P. Y. (2015). Evaluasi Penggunaan Obat dan Outcome Terapi Penyakit Diabetes Melitus Tipe 2 di Instalasi Rawat Inap Rumah Sakit Umum Negara, Bali. Jurnal. Universitas Gadjah Mada.

PERKENI. 2015.Pengelolaan dan Pencegahan Diabetes Melitus Tipe 2 Di Indonesia 2015. PB. PERKENI.

Rasdianah, N., Martodiharjo, S., Andayani, T. M., \& Hakim, L., 2016. Gambaran Kepatuhan Pengobatan Pasien Diabetes Melitus Tipe 2 di Puskesmas Daerah Istimewa Yogyakarta. Jurnal Farmasi Klinik 